\title{
DIREITO FUNDAMENTAL AO ESQUECIMENTO: INFLUENCIA DA INTERNET E CRÍTICA AO MÉTODO DECISIONAL DOS TRIBUNAIS BRASILEIROS
}

\section{FUNDAMENTAL RIGHT TO OBLIVION: INFLUENCE OF THE INTERNET AND CRITICAL DO THE DECISIONAL METHOD IN BRAZILIAN COURTS}

\author{
Roger de Moraes de Castro ${ }^{1}$ \\ Guilherme Pittaluga Hoffmeister ${ }^{2}$
}

\section{RESUMO}

A internet alterou completamente o modelo organizacional da sociedade. Desfez barreiras geográficas e possibilitou a disseminação imediata da informação em âmbito mundial. Não raramente, a alteração da sociedade faz com que direitos fundamentais entrassem em colisão. Dessa forma, o presente trabalho, pretende trabalhar com a colisão de alguns direitos fundamentais, especialmente envolvendo o esquecimento, expondo a maneira a qual os tribunais vêm decidindo esses conflitos e, por fim, fazendo uma análise crítica do método empregado pelo Tribunais brasileiros para se chegar a decisões que englobam esse direito fundamental. Para tanto, utilizar-se-á da revisão bibliográfica e do método fenomenológico hermenêutico.

Palavras-chave: Internet; Direito ao Esquecimento; Direitos Fundamentais; Colisão; Decisão.

\begin{abstract}
The internet has completely changed the organizational model of society. Undid geographic barriers and allowed the immediate dissemination of information worldwide. The change of society makes fundamental rights come into collision. Thus, the present study intends to work with the collision of some fundamental rights, especially involving the right to oblivion, exposing the manner in which the courts have decided these conflicts and, finally, making a critical analysis of the method used by the brazilian courts to arrive the decisions that encompass this fundamental right. To do so, we will be using the literature review and the hermeneutic phenomenological method.
\end{abstract}

Keywords: Internet; Right to Oblivion; Fundamental Rights; Collision; Decision.

\footnotetext{
${ }^{1}$ Mestrando no Programa de Pós-graduação em Direito na Universidade Federal de Santa Maria - UFSM, Rio Grande do Sul, (Brasil). Advogado no Escritório Leonardo Santiago Roger de Castro Advocacia Penal Empresarial. E-mail: roger@penalempresarialsm.com.br

${ }^{2}$ Mestrando no Programa de Pós-graduação em Direito na Universidade Federal de Santa Maria - UFSM, Rio Grande do Sul, (Brasil). Advogado no Escritório Hoffmeister e Souza Goulart Advocacia Criminal. Email: gphoffmeister@hotmail.com
} 


\section{INTRODUÇÃO}

A internet revelou-se como uma importante ferramenta para diminuir as distâncias e aumentar a possibilidade de comunicação entre os internautas. Ao mesmo tempo, contribuiu para a formação de um lugar de fácil hiperexposição e consequente vigilância por parte dos demais internautas e autoridades.

Por ser, a internet, um espaço que não encontra barreiras geográficas, possibilita extrema interação entre os usuários, uma vez que os indivíduos, ao contrário das mídias tradicionais, deixam de ser apenas receptores para tornarem-se emissores de informações, pensamentos, desejos, anseios ou ideias. Essa emissão pode se dar a partir de sua própria consciência, ou através do simples compartilhamento de ideias advindas de terceiros.

Nesse contexto cibernético, é necessário se ter presente que, ao mesmo tempo em que a interação entre usuários é permitida, a dignidade da pessoa humana - abarcando os conceitos de intimidade e privacidade - fica em segundo plano. Logo, iniciam-se os conflitos de direitos fundamentais entre o cidadão que deseja ter sua intimidade resguardada e as liberdades de expressão, informação e de imprensa, que projetam fatos lícitos, ou não, ao mundo online.

Daí, surge o direito ao esquecimento no âmbito da sociedade em rede. Um direito que pretende resolver os conflitos de direitos fundamentais, buscando salvaguardar os direitos da personalidade, procurando fazer com que fatos ligados à intimidade e à privacidade de determinado indivíduo não sejam mais noticiados, relembrados e perpetrados no tempo.

Diante disso, o presente trabalho tem por objetivo analisar o direito ao esquecimento, especialmente no âmbito informacional, em face dos conflitos de interesses constitucionais. Para tanto, entende-se que a utilização do método fenomenológico hermenêutico é a mais adequada para tanto, em conjunto com a revisão bibliográfica.

Para tanto, busca-se demonstrar a legislação existente no Brasil e a maneira com que os principais tribunais brasileiros vêm decidindo, fazendo-se um paralelo com os principais tribunais do mundo. O primeiro capítulo visa a apresentar um panorama geral da influência da internet na sociedade em rede e dos reflexos observados por essa tecnologia no âmbito legal. $\mathrm{O}$ segundo capítulo visa a apresentar o direito ao esquecimento enquanto direito fundamental, seus conflitos com a mídia e examinar a legislação existente sobre o tema no Brasil, nos Estados Unidos e na Europa. O terceiro capítulo busca compreender o método jurisdicional utilizado para solucionar os conflitos relativos ao direito ao esquecimento no Brasil. O quarto e último capítulo do presente trabalho visa a fazer uma crítica quanto ao uso do método da ponderação 
e sua inadequação frente ao modelo de estado democrático de direito brasileiro. Após uma conjugação desses pontos, busca-se fazer a crítica ao método utilizado pelos tribunais brasileiros para decidir a aplicação do direito ao esquecimento.

\section{DAS INOVAÇÕES ATRAÍdAS PELA INTERNET E OS SEUS REFLEXOS NO ÂMBITO LEGAL.}

O presente capítulo visa a apresentar um panorama geral da influência da internet na sociedade em rede e dos reflexos observados por essa tecnologia no âmbito legal. O advento da internet constituiu uma importante ferramenta para a revolução que eclodiu na sociedade atual, denominada de revolução informacional. A internet, dessa forma, consiste em um mecanismo que acabou por facilitar inúmeros aspectos na vida em sociedade, isso porque propiciou facilidade no alcance das informações e ofereceu um contato facilitado entre os internautas. Esse ambiente oferece ao usuário a condição de interlocutor, possibilitando a manifestação e transmissão de suas ideias, críticas e ideais. Essas mudanças perpetradas parecem ser permanentes e irreversíveis.

Hoje, a internet é um novo meio de convívio, que é causa e efeito da formação de uma nova forma de organização social, a qual é chamada por Castells de sociedade em rede. Tanto é assim que a era da internet foi aclamada como o fim da geografia. De fato, a internet tem uma geografia própria, uma geografia feita de redes que processam o fluxo de informação gerados e administrados a partir de todos e quaisquer lugares (CASTELLS, 2003, p. 170). Nesse viés, a internet se constrói, no ambiente das relações virtuais, enquanto um novo meio para a socialização, isto é, para amizades, contatos profissionais, e outras relações próprias da sociedade em rede.

Apesar dessa ferramenta ter representado um avanço bastante significativo, alterando radicalmente o quadro informacional e permitindo que a informação seja descentralizada, democratizada e permissiva de uma interação mundial, cabe analisar os reflexos da internet na sociedade, compreendendo, mormente, que não trouxe somente efeitos positivos.

A respeito dos reflexos da internet na sociedade civil, desde uma perspectiva realista, talvez mais pessimista, pode-se dizer que a internet consiste na melhor e na pior coisa do mundo. $\mathrm{O}$ progresso de uma comunicação sem limites e o desastre, a colisão, mais dia menos dia, desse Titanic da navegação virtual com um iceberg. 
Maria Eduarda Gonçalves (2003) ao fazer menção acerca dos problemas jurídicos suscitados pela utilização da informática e pelo desenvolvimento do mercado da informação, bem como pela internet, dispõe que, além de serem relativamente recentes, não encontram respostas claras e sequer definidas pelo ordenamento jurídico existente (VIRILIO, 1999).

Em sendo assim, é necessário que o direito abalize novas probabilidades que a sociedade atual, com advento da internet, vem exigindo. Essa adaptação do direito à atualidade é ilustrada por Angela Espíndola e Priscila Werner (2006, p. 77):

\begin{abstract}
O contexto atual da sociedade contemporânea exige do direito novas perspectivas no que concerne à forma de pensar, aplicar e interpretar a lei. Assim, o direito para atender os clamores da sociedade onde tudo é urgente e incerto, precisa adaptar-se as essas novas exigências. Entretanto, isso somente é possível quando se (re)pensa criticamente alguns conceitos e dogmas vigentes na ciência jurídica. Assim, o direito e seu processo enquanto instrumento para a pacificação dos conflitos sociais, prescindem de uma abertura às transformações sociais para encontrar novas respostas.
\end{abstract}

Da mesma maneira que a Internet traz incontáveis benefícios, ela desafia os Estados a criar um método de controle de conteúdo. Veja-se que a internet não exige somente novas soluções jurídicas para os novos problemas, mas ela também afeta a maneira de como os problemas e as soluções devem ser analisadas. (LEONARDI, 2011, p. 39)

É necessário frisar que, na internet, o emissor e o receptor da mensagem, não possuem qualquer controle sobre a amplitude e a divulgação dessa mesma mensagem dentro da sociedade em rede. Uma informação posta na rede pode se espalhar de maneira infinita por todo o mundo, sem qualquer controle externo.

Nesse aspecto é que surge o conflito existente entre direitos fundamentais, facilmente identificado no âmbito da sociedade em rede, como é o caso da liberdade de imprensa versus o da dignidade humana, que acolhe, em seu cerne, o tema do direito ao esquecimento.

\title{
2 DO DIREITO AO ESQUECIMENTO.
}

Considerando a qualidade de rede global aberta, por princípio, a qualquer cidadão, a internet tem suscitado um vivo debate entre direitos fundamentais, tendo alguns temas conquistado relevância. É o caso do conflito existente entre a liberdade de imprensa e o direito à intimidade, ambos previstos pela Constituição Federal. A liberdade de imprensa, revela-se, de certa forma, incensurável e goza de uma liberdade plena. Já o direito à intimidade, é abarcado pela dignidade da pessoa humana. Nesse sentido, este capítulo visa a apresentar o direito ao 
esquecimento enquanto direito fundamental, seus conflitos com a mídia e examinar a legislação existente sobre o tema no Brasil, nos Estados Unidos e na Europa.

Assim, quando um cidadão tem seu nome entrelaçado a fato lícito ou ilícito, pretérito ou presente e, que de alguma maneira, poderá prejudicá-lo intimamente, ou perante terceiros, ou a si próprio, é seu direito querer que tal fato seja esquecido.

Nessa situação, surge um "novo" direito, qual seja, o direito ao esquecimento, que tem por objetivo a proteção da intimidade, da vida privada e da memória individual frente à propagação, na sociedade em rede, de fatos que interessam apenas à esfera privada ou íntima do indivíduo.

Necessário situar o direito ao esquecimento no tempo, já que não se trata de um direito que surgiu com o advento da Internet. Por se tratar de uma questão intimamente ligada à privacidade, é uma matéria antiga que, de tempos em tempos, com a evolução da sociedade e da tecnologia, vai sendo analisada de outras maneiras e sob outras perspectivas.

Para se ter uma ideia temporal, no século XIX, com a invenção da máquina de fotografia instantânea e com o desenvolvimento dos jornais, a doutrina norte-americana começou a compor teses sobre o "direito de ser deixado em paz", na tentativa de suprir a carência doutrinária e jurisprudencial. Buscava-se, na época, prever alguma solução legal às intimidações que a sociedade começava a sofrer com essa nova tecnologia.

A partir daí, com toda evolução conhecida, com todo o desenvolvimento tecnológico existente, viu-se surgir os problemas de privacidade que, até então, eram inimagináveis, propiciados, principalmente, pela velocidade de compartilhamento de informações, unindo veículos de comunicação à notícia instantânea, às redes sociais, e inúmeros aplicativos aptos a compartilharem toda e qualquer informação. Os meios de comunicação atuais são múltiplos, e, consequentemente, o são, também, os conflitos surgidos a partir deles.

Dessa forma, tem-se, hoje, como um dos grandes desafios da comunidade jurídica, buscar soluções para os conflitos surgidos entre os direitos da personalidade e as liberdades constitucionais, dentre esses, a questão do direito ao esquecimento.

\subsection{Direito ao Esquecimento em Conflito com a Mídia.}

Uma das principais discussões a respeito do direito ao esquecimento é o quanto esse direito interfere na questão da liberdade de imprensa. É inegável que há conflitos entre os 
direitos individuais e os diretos de liberdade de informação/expressão englobados pela liberdade de imprensa, ainda mais quando levado ao plano da sociedade em rede.

Esse tema é ratificado por Valéria do Nascimento e Márcio Rodrigues (2014. p. 169): "Na mesma medida em que cresce o número de usuários e de informações lançadas na Internet, aparecem conflitos gerados por esse manancial de dados que, em última análise, podem servir de instrumento de invasão na privacidade das pessoas".

Assim, considerando que o direito ao esquecimento é uma forma de assegurar os direitos individuais frente às liberdades constitucionais e os direitos da coletividade, alguns entendem que esse "novo" direito pode, por vezes, trabalhar como uma ferramenta de censura, ou uma espécie de "queima de arquivo".

Essa discussão se alvoroça ainda mais quando se busca o esquecimento de um dado obtido licitamente por terceiro, um dado histórico ou uma informação/notícia de relevância para o cunho jornalístico, o que faz com que o direito ao esquecimento seja matéria em ascensão nos tribunais brasileiros.

Porém, apesar do crescimento de tal discussão, não contamos com uma jurisprudência pacífica, além de haverem pouquíssimos julgamentos com trânsito em julgado. Da mesma maneira, nossa legislação.

Tais deficiências e lacunas, como se verá, inegavelmente, expõem a sociedade e os jurisdicionados a uma completa ausência de parâmetros onde basear suas pretensões e anseios, expondo-os, igualmente, à absoluta insegurança jurídica, pois, uma vez que não há regras explícitas onde aparar-se, fica-se à mercê de julgados sem embasamento concreto, apenas sujeitos à convicção momentânea do magistrado. Tendo em vista que outros países, principalmente os europeus, possuem grande vantagem sobre o Brasil nesse ponto, importante trazer a experiência estrangeira para bem analisar-se o tema e encontrar subsídios suficientes para a preparação de uma evolução legislativa e jurisdicional que o tema merece.

\subsection{A Legislação sobre o Direito ao Esquecimento no Brasil, nos Estados Unidos e na Europa.}

A introdução específica do Direito ao Esquecimento no ordenamento jurídico brasileiro se deu através do Enunciado 531, do Conselho da Justiça Federal, aprovado em 2013, com o seguinte conteúdo: 
ENUNCIADO 531 - A tutela da dignidade da pessoa humana na sociedade da informação inclui o direito ao esquecimento.

Justificativa: Os danos provados pelas novas tecnologias de informação vêm se acumulando nos dias atuais. O direito ao esquecimento tem sua origem histórica no campo das condenações criminais. Surge como parcela importante do direito do exdetento à ressocialização. Não atribui a ninguém o direito de apagar fatos ou reescrever a própria história, mas apenas assegura a possibilidade de discutir o uso que é dado aos fatos pretéritos, mais especificamente o modo e a finalidade com que são lembrados. (BRASIL, 2013a, s.p.).

Apesar desse enunciado não ter força mandatória, ele, por vezes, é utilizado para justificar uma interpretação na solução de uma lacuna da lei, além disso, a existência dele, por si só, chama atenção para necessidade de se pensar no direito ao esquecimento como uma fonte de preservação dos direitos fundamentais do cidadão.

Além disso, o Marco Civil da Internet (BRASIL, 2014, s.p.) trata do Direito ao Esquecimento no seu artigo $7 .^{\circ}$, inciso $\mathrm{X}$ - ainda que não utilize a expressão "direito ao esquecimento" - assegurando o direito ao usuário de ter excluído, de maneira definitiva, seus dados pessoais:

Art. 7. ${ }^{\circ} \mathrm{O}$ acesso à internet é essencial ao exercício da cidadania, e ao usuário são assegurados os seguintes direitos: $\mathrm{X}$ - exclusão definitiva dos dados pessoais que tiver fornecido a determinada aplicação de internet, a seu requerimento, ao término da relação entre as partes, ressalvadas as hipóteses de guarda obrigatória de registros previstas nesta Lei. (BRASIL, 2014, s.p.)

Nessa previsão legal feita pelo Marco Civil, chama a atenção o fato de serem utilizadas as palavras "exclusão definitiva". O termo, exclusão definitiva, quando faz referência a conteúdo disponibilizado na internet, não é bem-vindo. Isso porque, a sociedade em rede, como anteriormente afirmado, foi aclamada como o fim da geografia, como um mecanismo sem barreiras, de hiperexposição e de baixíssimo controle.

Em outra perspectiva, o direito ao esquecimento é previsto de maneira implícita na lei penal. Tal se dá através do instituto da prescrição, ou do artigo $93^{3}$ do Código Penal que trata sobre a reabilitação, assegurando o sigilo dos registros sobre o processo e condenação do indivíduo que fora condenado.

\footnotetext{
${ }^{3}$ Cuja redação é: “A reabilitação alcança quaisquer penas aplicadas em sentença definitiva, assegurando ao condenado o sigilo dos registros sobre o seu processo e condenação. (Redação dada pela Lei $\mathrm{n}^{\circ}$ 7.209, de 11.7.1984) Parágrafo único - A reabilitação poderá, também, atingir os efeitos da condenação, previstos no art. 92 deste Código, vedada reintegração na situação anterior, nos casos dos incisos I e II do mesmo artigo".
} 
Ainda, o art. $202^{4}$ da lei de execuções penais, $n^{\circ} 7.210 / 84$, estabelece que, após a extinção da pena, não deve constar na folha corrida judicial do apenado qualquer notícia sobre a condenação que lhe foi imposta no passado, salvo para instruir processo por nova infração penal, ou outros casos expressos na lei.

Ademais, existe uma série de projetos de lei quando o assunto se refere a direito ao esquecimento. Um deles, projeto 1.676 de 2015, apresentado pelo Deputado Federal Veneiano Vital, do PMDB, propõe a obrigação dos meios de comunicação social do Brasil em criar uma espécie de call center, além de disponibilizar endereço comercial para que as pessoas, que desejam apagar seus nomes de notícias veiculadas no passado, possam ser ouvidas (BRASIL, 2015, s.p.).

De outro modo é tratado o direito ao Esquecimento nos Estados Unidos. Apesar de o assunto em pauta já ser íntimo dos Tribunais norte-americanos, tanto as decisões, quanto a legislação que trata acerca do tema sustentam posição firme no sentido de que, quando em jogo o direito subjetivo do cidadão ao esquecimento e à liberdade de imprensa, impera a tradição político-jurídica do país, sempre priorizando as liberdades de expressão e de imprensa (FERREIRA, 2012).

A mencionada tradição do país no tocante à preferência, quase que de forma pacífica, às liberdades de expressão e de imprensa, pode ser vista, até mesmo, a partir da leitura da Constituição norte-americana, tendo em vista que essa sequer prevê regramentos acerca da privacidade do cidadão. Dessa forma, o cidadão se percebe absolutamente carente de proteção legal, sendo flagrante a predileção dos EUA pela mais ampla livre circulação da informação (FERREIRA, 2012).

Tal carência legislativa sobre o direito ao esquecimento já foi, por muitas vezes, debatida no Congresso, contudo, sem obter retorno positivo. Isso se deu, principalmente, por falta de apoio dos grandes grupos econômicos, que temiam efeitos negativos em seu negócio, a partir da mudança na legislação (FERREIRA, 2012).

Somado a isso, tem-se a desconfiança que tal alteração ainda logra, tendo em vista imperar a tradição sobre a mudança de paradigmas. Ademais, há que se destacar que a ausência de freios no tocante à invasão da privacidade dos norte-americanos se potencializou com o episódio ocorrido em 11 de setembro, e com as milhares de ameaças posteriores de ataques

\footnotetext{
${ }^{4}$ Cumprida ou extinta a pena, não constarão da folha corrida, atestados ou certidões fornecidas por autoridade policial ou por auxiliares da Justiça, qualquer notícia ou referência à condenação, salvo para instruir processo pela prática de nova infração penal ou outros casos expressos em lei”.
} 
terroristas, existindo uma união de esforços de diversos setores, como, bancos, companhias aéreas e empresas de telecomunicações, a fim de colher informações dos usuários e cruzar as referidas informações, e detectar possíveis planejamentos de ataques (FERREIRA, 2012).

Todos esses elementos configuram entraves à concretização de uma verdadeira mudança legislativa e, também, e principalmente, de postura no tocante à proteção da privacidade, a partir da devida disciplina do direito ao esquecimento. Enquanto isso, a regra, baseada na Primeira Emenda à Constituição dos EUA, é que, tendo um Website informações sobre um indivíduo, não há qualquer impedimento deste publicá-las, salvo raras exceções (FERREIRA, 2012).

As poucas, e pouco aplicáveis, exceções têm por base a teoria desenvolvida por Samuel Warren e Louis Brandeis, que deu origem aos privacy torts (delitos de liberdade), encontrando-se, dentre esses, o delito da divulgação pública de fatos privados, que se consubstancia com a proibição da publicação de fatos relativos à vida privada dos indivíduos que sejam ofensivos ou que não demonstrem interesse ao público, acarretando, quando da publicação indevida, a responsabilização do órgão de comunicação (FERREIRA, 2012).

Contudo, há uma certa resistência por parte dos Tribunais em classificar uma informação como não sendo de interesse do público e, a partir disso, promover a responsabilização do órgão comunicador. As decisões com tal repetição de posicionamento são diversas, sendo que, em cada uma delas, percebe-se a inclinação do Tribunal em justificar, de alguma forma, a permissão da publicação das informações e, consequentemente, a proteção da liberdade de imprensa em detrimento do direito ao esquecimento, bastando, para tanto, que a informação seja verdadeira e tenha sido obtida por meios lícitos (FERREIRA, 2012).

Em sentido contrário aos Estados Unidos, a Comunidade Europeia trata do direito ao Esquecimento com maior amplitude e de forma mais avançada na legislação. Muito por sua tradição que é baseada no civil law, diferentemente do sistema estadunidense, fundamentado na jurisprudência - common law (PARENTONI, 2015, p. 566).

Na Europa, a diretiva n ${ }^{\circ}$ 1995/46/CE, surge como principal referência de tratamento de dados pessoais. Apesar de não tratar especificamente do direito ao esquecimento, seus princípios gerais amparam esse direito. Exemplo disso, é o princípio do consentimento que permite ao sujeito interessado requerer ao mantenedor de seus dados pessoais esclarecimentos a respeito da forma como são armazenados e utilizados, podendo até mesmo exigir remoção dos dados (PARENTONI, 2015, p. 574). 
Em 2002, já com a diretiva de 1995 desatualizada, devido ao avanço da Internet e do fluxo de dados pessoais na rede, a Comunidade Europeia editou uma diretiva complementar, conhecida como e-Privacy Directive, que tratava especificamente do processamento eletrônico, e que trazia no seu artigo 6 a previsão de que os dados pessoais deveriam ser apagados ou tornados anônimos quando não mais subsistir a razão pela qual foram coletados (PARENTONI, 2015, p. 573).

Em 2009, a França propôs novas mudanças no marco normativo europeu, que continha um código de conduta aos prestadores de serviço da internet, sobre o modo como deveria ser feito o tratamento de dados pessoais, com o fim de assegurar a privacidade dos usuários, bem como o direito ao esquecimento. Importante referir que a proposta não foi aceita pelos dois maiores expoentes da internet: Google e Facebook (PARENTONI, 2015, p. 571).

Em 2010, na mesma diretiva proposta pela França, a Comissão do Parlamento Europeu e o Conselho da União Europeia elaboraram documento com a definição comunitária do direito ao esquecimento no âmbito eletrônico. Tal documento foi denominado de "Uma abordagem global da proteção de dados pessoais na União Europeia” (PARENTONI, 2015, p. 571).

A Europa, sempre muito preocupada com o direito individual do cidadão e o trato do direito ao esquecimento, principalmente dos dados pessoais, continuou a evoluir. Tanto é assim, que em 2012 lançou o comunicado número 2012/11/CE, que substitui a Diretiva 1995/46/CE por um Regulamento - que visava assegurar a uniformidade na aplicação de normas entre os Estados-membros (PARENTONI, 2015, p. 572).

Importa destacar que tal substituição da Diretiva pelo Regulamento deu-se com vistas a modificar a forma de aplicação do conteúdo do regramento, uma vez que, enquanto a Diretiva apenas enuncia princípios e parâmetros gerais, conferindo maior discricionariedade no momento da aplicação pelos Estados-membros, o Regulamento é autoaplicável a todos os Estados-membros, produzindo efeitos desde o momento de sua edição, o que, por sua vez, confere maior uniformidade, evitando a disciplina diversa de matéria idêntica, o que reduz, consequentemente, as omissões e conflitos entre as legislações nacionais (PARENTONI, 2015).

Ademais, os Regulamentos apresentam propostas cruciais no que tange à ampliação e aprimoramento no âmbito da proteção do direito ao esquecimento. Dentre essas, destaca-se o aprimoramento dos Princípios do consentimento e da finalidade. Por meio da aplicação do primeiro, exige-se a autorização prévia do sujeito detentor dos dados, para que seja possível todo e qualquer tratamento relativo a esses, além de permitir a solicitação de esclarecimentos, correção, bloqueio do acesso aos dados ou remoção dos mesmos, por parte de interessado 
relacionado às informações. Já, o segundo, determina que os dados pessoais devem ser armazenados somente enquanto úteis dentro do contexto em que foram coletados, eliminandose acontecimentos passados e inúteis em contextos atualizados, por pedido do sujeito interessado (PARENTONI, 2015, p. 573-5).

Outra proposta é a ampliação do rol dos dados pessoais sensíveis, atualizando-o às necessidades da atualidade, com a inclusão, por exemplo, da proteção do patrimônio genético, dos dados biométricos, além da introdução do direito da portabilidade do perfil do internauta, de uma plataforma a outra (right to data portability), permitindo a transferência automática de perfil a uma nova plataforma, independentemente da diferença de configuração (PARENTONI, 2015 p. 573-4).

Verifica-se, pois, que, em contrapartida da tendência mundial no tocante à evolução legislativa sobre o tema, bem como no desenvolvimento de instrumentos aptos a aumentarem a proteção e diminuírem os conflitos resultantes das lacunas e consequentes abusos de direitos fundamentais, encontram-se a legislação pátria e as respectivas políticas públicas desenvolvidas acerca da temática em questão. Isso só faz demonstrar que o país ainda engatinha na evolução da abordagem e enfrentamento do tema, enquanto a sociedade, em constante ritmo evolutivo e de modificação, sobrevive, com todas as difíceis consequências, sem a devida disciplina de tão importante e atual matéria, assumindo, assim, os Tribunais, o inapropriado papel de "legislador", a fim de dirimir as tantas lacunas surgidas quando do enfrentamento da questão.

\section{DO MÉTODO JURISDICIONAL BRASILEIRO PARA SOLUCIONAR CONFLITOS.}

O presente capítulo busca compreender o método jurisdicional utilizado para solucionar os conflitos relativos ao direito ao esquecimento no Brasil. Observando-se os julgados do Superior Tribunal de Justiça que tratam do direito ao esquecimento e o consequente conflito de direitos fundamentais, verifica-se que a matéria vem sendo resolvida através da utilização da ponderação entre o direito individual do cidadão (como intimidade, privacidade e honra) de ter o fato esquecido e o interesse coletivo de não ter a história apagada.

Prova disso, é o julgamento do Recurso Especial n. ${ }^{\circ}$ 1.334.097, de relatoria do Ministro Luis Felipe Salomão (onde a matéria em discussão está relacionada a um caso que envolve direito da personalidade do autor da ação, frente à liberdade de imprensa de exibir documentário em rede nacional), onde o eminente relator afirma ser necessária a utilização da ponderação para se chegar à resposta final. 
Senão, veja-se trecho do voto:

Com efeito, no conflito entre a liberdade de informação e direitos da personalidade aos quais subjaz a proteção legal e constitucional da pessoa humana -, eventual prevalência pelos segundos, após realizada a necessária ponderação para o caso concreto, encontra amparo no ordenamento jurídico, não consubstanciando, em si, a apontada censura vedada pela Constituição Federal de 1988. (BRASIL, 2013b) (Grifei).

No referido caso, o autor da ação cível fora acusado de participar do assassinato de moradores de rua, conhecido como "chacina da candelária", ocorrido em 1993. No transcurso da ação penal, o autor fora absolvido, tendo sua inocência comprovada. Após isso, um programa de televisão, chamado Linha Direta, exibido pela Ré, Globo Comunicações e Participações S/A, procurou o Autor para entrevistá-lo sobre o caso, o que foi negado pelo próprio. Ainda assim, em junho de 2006, o programa mencionado foi veiculado em rede nacional, e o autor da ação apontado como um dos envolvidos no crime - apesar da referência à absolvição. Por conta desse episódio, o Autor sofreu diversos constrangimentos, tendo que se mudar do local onde residia por medo de ser morto pelos “justiceiros”. Em decorrência disso, ingressou com ação judicial, fundamentando-a com base, também, no direito ao esquecimento. Tal ação foi provida.

Importante destacar outro notável caso ocorrido no Brasil, no qual se verifica a incidência do direito ao esquecimento e a colisão de direitos fundamentais. Trata-se do "Caso Doca Street”. Nesse, o autor da ação, Raul do Amaral Street, popularmente conhecido como Doca Street, condenado a 15 anos de prisão pelo assassinato da socialite mineira Ângela Diniz, ocorrido em 1976, demandou contra a mesma rede Globo de TV, requerendo indenização por danos morais, em virtude de sua história ter sido veiculada no programa Linha Direta, da emissora. $\mathrm{O}$ autor conseguiu, em segundo grau, obter a indenização de $\mathrm{R} \$ 250$ mil reais, tendo o tribunal carioca entendido que houve abuso na produção e divulgação do programa, porquanto o acusado já havia cumprido pena e sido reintegrado à sociedade, de modo que a sua condição de ex-criminoso não poderia ser utilizada ao sabor dos interesses comercias da empresa televisiva, não se adequando o fato como exercício da liberdade de imprensa.

Por fim, outro caso julgado pelo STJ de repercussão nacional, que, igualmente, invocou o direito ao esquecimento, ficou conhecido como o "Caso Aida Curi", devido à situação como ocorreu e pela força do noticiário.

Aida foi vítima de crime brutal de homicídio, tendo sido sexualmente violentada por três homens, os quais, na tentativa de encobrir o crime, tentaram simular um suicídio, atirandoa do décimo segundo andar de um prédio no badalado bairro de Copacabana no Rio de Janeiro. 
Tal fato foi noticiado anos depois, pela Globo Comunicações e Participações S/A, em seu programa Linha Direta Justiça, motivo pelo qual os irmãos da vítima ingressaram com ação de reparação de danos materiais e morais, alegando que o fato fora esquecido no tempo, sendo que a divulgação do programa reabriu antigas feridas, expondo indevidamente a vítima e familiares, com objetivo único de exploração comercial e econômica. Já em primeira instância o pedido fora julgado improcedente, tendo seguido assim até o Julgamento no Superior Tribunal de Justiça, em que o Relator negou provimento ao recurso, inclusive com relação à indenização por dano moral, tendo em vista que, no caso, o acolhimento ao direito ao esquecimento seria desproporcional frente à liberdade de imprensa, se comparado ao desconforto gerado pela lembrança, e pelo fato da imagem da falecida não ser utilizada de maneira degradante ou desrespeitosa. Para se chegar a essa decisão, igualmente, o Relator do recurso fez uso da ponderação, veja-se:

\footnotetext{
A reportagem contra a qual se insurgiram os autores foi ao ar 50 (cinquenta) anos depois da morte de Aida Curi, o que me faz concluir que não há o abalo moral. Nesse particular, fazendo-se a indispensável ponderação de valores, o acolhimento do direito ao esquecimento, no caso, com a consequente indenização, consubstancia desproporcional corte à liberdade de imprensa, se comparado ao desconforto gerado pela lembrança. (BRASIL, 2013b).
}

Claro que a utilização do método da ponderação para decidir casos que versam sobre os conflitos de direitos fundamentais, como é o caso do direito ao esquecimento, é corroborada por um número expressivo de doutrinadores brasileiros. Exemplificativamente, colaciona-se o entendimento do escritor Luis Alberto Barroso:

Na colisão entre a liberdade de informação e de expressão, de um lado, e os direitos da personalidade, de outro, destacam-se como elementos de ponderação: a veracidade do fato, a licitude do meio empregado na obtenção da informação, a personalidade pública ou estritamente privada da pessoa objeto da notícia, o local do fato, a natureza do fato, a existência de interesse público na divulgação, especialmente quando o fato decorra da atuação de órgãos ou entidades públicas, e a preferência por medidas que não envolvam a proibição prévia da divulgação. Tais parâmetros servem de guia para o intérprete no exame das circunstâncias do caso concreto e permitem certa objetividade às suas escolhas. (BARROSO, 2001, s.p).

Ocorre que a utilização da ponderação, seja nos conflitos de direitos fundamentais interligados com o direito ao esquecimento ou em qualquer outro conflito, na visão desse autor e sedimentada pelos ensinamentos de Ronald Dworkin, Lenio Streck e Cristiano Isaia, é medida desonesta e inaceitável em um país como o Brasil, que se diz democrático. Isso porque, aceitar 
a ponderação é consentir com o protagonismo judicial - leia-se, protagonismo de um servidor público que decide conforme sua consciência.

\title{
4 CRÍtICA QUANTO AO USO DO MÉTODO DA PONDERAÇÃO E SUA INADEQUAÇÃO FRENTE AO MODELO DE ESTADO DEMOCRÁTICO DE DIREITO BRASILEIRO.
}

O método da ponderação foi utilizado pela primeira vez no Tribunal Constitucional Federal Alemão na sentença Luth em 1958, na qual ponderou-se e decidiu-se sobre a constitucionalidade de restrição a direito fundamental. O Tribunal Alemão decidiu, com base nas circunstâncias do caso concreto, que o direito fundamental à liberdade de expressão deveria prevalecer, uma vez que não comprometia interesse de terceiros dignos de proteção. (ANTUNES, 2006). O presente capítulo visa a fazer uma crítica quanto ao uso do método da ponderação e sua inadequação frente ao modelo de estado democrático de direito brasileiro.

A ponderação está intimamente ligada com a impossibilidade da lei brasileira em prever todos os problemas de uma sociedade cada vez mais complexa. Surge como um critério interpretativo da lei para solução de casos em que é impossível aplicar a subsunção da norma ao caso concreto, por haver conflitos de normas.

George Marmelstein (2013, p. 378), nesse sentido, expõe:

\begin{abstract}
A ponderação é uma técnica de decisão empregada para solucionar conflitos normativos que envolvam valores ou opções políticas, em relação aos quais as técnicas tradicionais de hermenêutica não se mostram suficientes. É justamente o que ocorre com a colisão de normas constitucionais, pois, nesse caso, não se pode adotar nem o critério hierárquico, nem o cronológico, nem a especialidade para resolver uma antinomia entre valores.
\end{abstract}

Motta, em sua obra Levando o Direito a Sério, estabelece que é preciso superar esse convívio pacífico que o Direito vem tendo com o protagonismo judicial, compreendido na seara de que os juízes, ao decidirem os casos difíceis, usem de sua moralidade individual ou de sua capacidade de discernimento (MOTTA, 2012, p. 101).

Tanto a ponderação Alexiana quanto a praticada pelos Tribunais do Brasil está atrelada à discricionariedade. Segundo o escritor Lenio Streck, a ponderação, como método que é, "tenta esconder, sob o véu da racionalidade, um subjetivismo que primeiro escolhe e depois, retoricamente, encontra uma justificação" (STRECK, 2014, p. 127). Com isso, o método da ponderação, abre uma gama imensa para a discricionariedade, na medida em que nesse método 
caberá tão somente ao julgador/intérprete hierarquizar e escolher qual direito fundamental deverá prevalecer no caso concreto.

A crítica que se faz é exatamente a utilização da ponderação, ou seja, de um método para se chegar a uma resposta do caso concreto. Fundamenta-se tal crítica baseando-se na ideia de que, a partir de tal procedimento, de confrontar um princípio com o outro, se está muito próximo da jurisprudência dos interesses, o que acaba dando condições ao desenvolvimento do ativismo judicial para além dos limites que são estabelecidos pela Constituição. (STRECK, 2014, p. 129).

Nesse aspecto, aliás, Lenio Luiz Streck assevera que o "direito não é (e não pode ser) aquilo que o intérprete quer que ele seja" (STRECK, 2012, p. 25), de modo que sustenta que grande parte dos magistrados brasileiros estão comprometidos apenas com sua consciência, fazendo uso da subjetividade e do poder discricionário para proferir suas decisões. (STRECK, 2014, p. 129).

A necessidade, portanto, de analisar a decisão judicial enquanto uma construção constitucional, rechaça, por si só, decisões apoiadas pelo método da ponderação que traz consigo ideias solipsistas, desprovidas de fundamentação constitucional, que relegam o caso concreto a segundo plano, fazendo eclodir, assim, decisões arbitrárias e com baixa constitucionalidade.

Veja-se, que o julgador, ao ponderar os direitos colidentes e, ao escolher qualquer deles para prevalecer, não está condicionando sua opção a pressupostos jurídicos e, sim, pela sua vontade e pela sua compreensão do que será melhor para aquele caso.

Para se chegar à resposta correta, segundo a teoria desenvolvida por Ronald Dworkin, é necessário utilizar-se da interpretação de acordo com a constituição. Justamente por isso é que a resposta não pode ser fruto da consciência do julgador e do seu livre convencimento. Para tanto, Dworkin, estabelece que o direito deve ser tratado com integridade e coerência, rechaçando o método subsuntivo-dedutivo, o qual prevê a possibilidade de se escolher entre uma gama de possibilidades.

Para tanto, Dworkin tenta aproximar o direito da literatura, criando o "romance em cadeia", um romance escrito coletivamente, em que será dado a cada juiz/escritor um capítulo para ser escrito e compor a referida obra. O argumento principal é que, cada juiz, antes de escrever seu capítulo, terá que ler o que os outros juízes escreveram nos capítulos anteriores para poder continuar a história. Nas palavras do próprio Dworkin (2001, p. 238): 


\begin{abstract}
Ao decidir o novo caso, cada juiz deve considerar-se como parceiro de um complexo empreendimento em cadeia, do qual essas inúmeras decisões, estruturas, convenções e práticas são a história; é seu trabalho continuar essa história no futuro por meio do que ele faz agora. Ele deve interpretar o que aconteceu antes porque tem a responsabilidade de levar adiante a incumbência que tem em mãos e não partir em alguma nova direção. Portanto, deve determinar, segundo seu próprio julgamento, o motivo das decisões anteriores, qual realmente é tomado como um todo, o propósito ou tema da prática até então.
\end{abstract}

É preciso deixar claro que essa ideia não se trata do juiz simplesmente se reportar a decisões passadas, padronizando as decisões. O que se deseja é uma decisão coerente com as decisões do passado, que respeite as tradições e seja fundada em princípios constitucionais.

A resposta correta, por assim ser, deve ser uma compreensão constitucional, como afirma Cristiano Becker Isaia "todo o caso concreto levado ao plano processual exige 'a' resposta constitucionalmente correta àquela situação conteudística (fática), que não é e nem pode ser fruto da repetição" (ISAIA, 2012, p. 234).

Para Lenio Streck, através da ponderação, seria impossível alcançar a resposta correta, vez que a interpretação do direito no Estado Democrático de Direito é incompatível com esquemas interpretativo-procedimentais que conduzam a múltiplas possibilidades de escolhas. Tal modelo se revela incompatível com aquele eleito pela nossa Constituição, revelando-se ilegítima qualquer tipo de "escolha" dentro do cenário constitucional atual, devendo as decisões serem baseadas em fundamentação concreta e legitimada pela Lei, excluindo-se qualquer tipo de discricionariedade a ser exercitada pelo magistrado.

\title{
CONCLUSÃO
}

Como ficou demonstrado, o advento das novas tecnologias, especialmente a Internet, trouxe grandiosos avanços à comunidade mundial. A sociedade que utiliza a internet, classificada como sociedade em rede, é marcada pela facilidade de disseminar informações e pensamentos.

Ocorre que algumas dessas informações perpetradas no âmbito informacional invadem a esfera privada de indivíduos que não desejariam ter informações e/ou notícias a seu respeito expostas por todos os cantos do mundo através da internet. Nesse compasso, tais indivíduos vêm buscando tutelar seus direitos fundamentais através da aplicação do direito ao esquecimento. Direito esse, que tenta restringir a propagação de informações obtidas lícita ou 
ilicitamente sobre fatos do passado ou presente, que agridam a intimidade e, até mesmo, a índole da pessoa envolvida.

O trabalho proposto pesquisou a maneira com que esse direito ao esquecimento vem sendo aplicado no Brasil, nos Estados Unidos e na Europa, trazendo divergentes aplicações. Porém, a questão a que se vincula tal pesquisa, está ligada com maior ênfase às decisões brasileiras e à justificativa da aplicação ou não de tal direito. Como relatado, o Superior Tribunal de Justiça, ao decidir casos que tenham ligação com esse direito ao esquecimento e, portanto, tratem sobre a colisão de direitos fundamentais, vem entendendo sobre a prevalência de um ou de outro direito com base no método da ponderação dos valores discutidos.

Conclui-se que, ao utilizar da ponderação, os juízes justificam suas decisões de maneira discricionária e desprovida de fundamentação legal. Ou seja, os valores utilizados pelo juiz ao ponderar (leia-se, escolher), qual direito prevalecer num determinado conflito provém de sua pré-compreensão, e, justamente por isso, é que a decisão que se chega com a ponderação é fruto da consciência do julgador, e não de uma intepretação de acordo com a constituição.

Dessa forma, tem-se que o julgador deve rechaçar a ponderação por ser um método discricionário que prevê que ele faça uma escolha dentro de uma gama de possibilidades. Ele não pode optar pelo direito individual do cidadão em ter determinado assunto esquecido com base na sua consciência do que é ou não mais benéfico para aquele caso concreto. $O$ julgador deve chegar à resposta correta sobre qual direito deve prevalecer levando em conta a constituição, a historicidade do direito e não a sua consciência.

Entende-se, assim, que a necessária compreensão da decisão judicial como ato de responsabilidade inserida em um contexto democrático deve levar o intérprete da norma a refutar toda e qualquer possibilidade do uso da discricionariedade no ato decisório, como é o caso da ponderação proposta nos casos de direito ao esquecimento colacionados ao presente artigo.

\section{REFERÊNCIAS}

ALMEIDA, Patricia Martinez; SILVEIRA, Vladmir Oliveira. O direito ao esquecimento e a privacidade. In: DE LUCCA, Newton; SIMÃO FILHO, Adalberto; LIMA, Cíntia Rosa Pereira. Direito e Internet III: Marco Civil da Internet III - tomo I. São Paulo: Quartier Latin, 2015, p.619642. 
ANTUNES, Roberta Pacheco. O princípio da proporcionalidade e sua aplicabilidade na problemática das provas ilícitas em matéria criminal. Disponível em <https://jus.com.br/artigos/8153/o-principio-da-proporcionalidade-e-sua-aplicabilidade-naproblematica-das-provas-ilicitas-em-materia-criminal>. Acesso em: 17 de jun. de 2016.

BARROSO, Luís Roberto. Colisão entre Liberdade de Expressão e Direitos da Personalidade. Critérios de Ponderação. Interpretação constitucionalmente adequada do Código Civil e da Lei de Imprensa. Disponível em: < http://www.migalhas.com.br/arquivo_artigo/art_0310-01.htm >. Acesso em: 17 de jun. 2016.

BRASIL. Câmara dos Deputados. Projeto de Lei n. ${ }^{\circ}$ 1.676. 2015. Tipifica o ato de fotografar, filmar ou captar a voz de pessoa, sem autorização ou sem fins lícitos, prevendo qualificadoras para as diversas formas de sua divulgação e dispõe sobre a garantia de desvinculação do nome, imagem e demais aspectos da personalidade, publicados na rede mundial de computadores, internet, relativos a fatos que não possuem, ou não possuem mais, interesse público. Disponível em: <http://www.camara.gov.br/proposicoesWeb/fichadetramitacao?idProposicao=1295741>. Acesso em: 10 maio de 2016.

Conselho da Justiça Federal - CJF. VI Jornada de Direito Civil. Enunciado 531. Brasília: 2013a. Disponível em: < http://www.cjf.jus.br/enunciados/enunciado/142>. Acesso em: 01 maio. 2016.

. Superior Tribunal de Justiça. Recurso Especial n 1.334.097 - RJ. Recorrente: Globo Comunicações e Participações S/A. Recorrido: Jurandir Gomes de França. 2013b. Disponível em: <https://ww2.stj.jus.br/revistaeletronica/Abre_Documento.asp?sSeq=1239004\&sReg=201201449 107\&sData=20130910\&formato=PDF $>$. Acesso em: 17 jun. 2016.

Superior Tribunal de Justiça. Recurso Especial no 1.335.153 - RJ RECORRENTE: Nelson Curi E Outros recorrido: Globo Comunicação E Participações S/A. Relator Ministro Luis Felipe Salomão. Julgado pela Quarta Turma. Disponível em: <http://s.conjur.com.br/dl/direito-esquecimento-acordao-stj-aida.pdf > Acesso em: 17 jun. 2016. 
CARVALHO NETO, Frederico da Costa. Novas ferramentas e privacidade. In Direito e novas tecnologias [Recurso eletrônico on-line] organização CONPEDI/UNINOVE; Coordenadores: Aires José Rover, Adalberto Simão Filho, Rosalice Fidalgo Pinheiro. Florianópolis: FUNJAB, 2013.

CARVALHO, Luis Gustavo Grandinetti Castanho de. Judiciário e novas mídias: garantias processuais e novas tecnologias. In. Direito e novas tecnologias da informação. Org. Rafael Santos de Oliveira. Curitibia: Íthala, 2015.

CASTELLS, Manuel. A galáxia da internet: reflexões sobre a internet, os negócios e a sociedade. Rio de Janeiro: Editora Zahar, 2003.

DWORKIN, Ronald. Uma questão de princípio. São Paulo: Martins Fontes, 2001.

ESPÍNDOLA, Angela Araújo da Silveira; WERNER, Priscila Cardoso. As tutelas de urgência como alternativa à superaçãoo do procedimento ordinário. In: Revista Eletrônica do Curso de Direito da UFSM. V.1, n.1, p.77, mar. 2006.

FERREIRA, João Gabriel Lemos. Os Direitos da Personalidade em evolução: o direito ao esquecimento. In Direito Civil. Publicação do XXII Congresso Nacional do CONPEDIUNICURITIBA.

Disponível

em <http://www.publicadireito.com.br/artigos/?cod=4a46fbfca3f1465a> Acesso em 30 de Abr. de 2016 (p. 94-120).

GONÇALVES, Maria Eduarda. Direito da Informação: Novos direitos e formas de regulação na sociedade da informação. Coimbra: Almedina, 2003.

ISAIA, Cristiano Becker. Processo civil e hermenêutica: a crise do procedimento ordinário e o redesenhar da jurisdição processual civil pela sentença (democrática) liminar de mérito. Curitiba: Juruá, 2012.

LEONARDI, Marcel. Tutela e Privacidade na Internet. São Paulo: Saraiva, 2012. 
MARMELSTEIN, George. Curso de Direitos Fundamentais. 4. ed. São Paulo: Atlas, 2013.

MELLO, Marco Antônio Machado Ferreira de. A tecnologia, direito e a solidariedade. In: Direito, sociedade e informática: limites e perspectivas da vida digital. Aires José Rover (org.) Florianópolis: Fundação Boiteux, 2000.

MOTTA, Francisco José Borges. Levando o Direito a Sério - Uma Crítica hermenêutica ao Protagonismo Judicial. 2aed. Porto Alegre: Livraria do Advogado, 2012.

NASCIMENTO, Váleria Ribas do; Marcio Schorn Rodrigues ;A sociedade informacional em xeque. Valéria Ribas do Nascimento. In: Mídia e direito na sociedade em rede. Org. Rafael Santos de Oliveira, Marília de Nardin Budó. Ijuí: Unijuí, 2014.

PARENTONI. Leonardo Netto. O direito ao esquecimento. In: Direito e Internet III Tomo I: Marco Civil da Internet (Lei n. 12.965/2014). DE LUCCA, Newton, SIMÃO FILHO, Adalberto, LIMA, Cintia Rosa Pereira de (coords.). São Paulo: Quartier Latin, 2015.

SARLET, Ingo Wolfgang. Dignidade da Pessoa Humana e Direitos Fundamentais na Constituição Federal de 1988. 4. ed. Porto Alegre: Livraria do Advogado, 2006.

Ingo Wolfgang. Tema da moda, direito ao esquecimento é anterior à internet. Revista Consultor Jurídico, 22 de maio de 2015. Disponível em: $<$ http://www.conjur.com.br/2015mai-22/direitos-fundamentais-tema-moda-direito-esquecimentoanterior-internet>. Acesso em: 28 abr. 2016.

SCHEREIBER, Anderson. Os direitos da personalidade. São Paulo: Atlas, 2011.

SIQUEIRA JR, Paulo Hamilton. Direitos humanos e cidadania digital. In: Direito e Internet III - Tomo I: Marco Civil da Internet (Lei n. 12.965/2014). DE LUCCA, Newton, SIMÃO FILHO, Adalberto, LIMA, Cintia Rosa Pereira de (coords.). São Paulo: Quartier Latin, 2015.

STRECK, Lenio Luiz. O que é isto - decido conforme a minha consciência? 3. ed. Porto Alegre: Livraria do Advogado. 2012.p. 25. 
Lenio Luiz. Lições de crítica hermenêutica do direito. Porto Alegre: Livraria do Advogado, 2014.

VIRILIO, Paul. A Bomba Informática. Tradução de Luciano Vieira Machado. São Paulo: Estação Liberdade, 1999. 